\title{
EFFECTS OF COLOURANTS ON QUALITATIVE PROPERTIES AND MARKETABILITY OF LIQUID DETERGENT
}

\author{
AKINYEMI O.P. \\ Chemical Engineering Department, Lagos State University \\ poakinyemi@yahoo.com; \\ Received: $14^{\text {th }}$ April 2019 \\ Accepted: $23^{\text {rd }}$ August 2019 \\ Published: $17^{\text {th }}$ September 2019 \\ https://doi.org/10.47545/etrj.2019.4.2.050
}

\begin{abstract}
Detergent can be defined as substance which improves the cleaning power of water by lowering its tension. The objective of this research work is to determine the effect of colorant on the quality and marketability of liquid detergent. In order to achieve this objective, the various constituent in required quantities were compounded to formulate a cleansing agent used in removal of dirt. Long chain organic acid was made to neutralise caustic soda and additives were added to the mixture obtained (at pH 6.8 to 7.2) to give required colours (pink, blue, green, glow green and yellow): formalin / methanol to prevent acidity as a germicidal and anti-bacterial agent and perfume, (rose, jasmine etc) to give the desired smell. The quality of various sample was tested and their marketability evaluated with questionnaire by the consumers. The result obtained showed that colorant does not have any negative effect on the quality of the liquid detergent produced. However, it was observed from data obtained from the consumers, that yellow coloured liquid detergent was most preferred. It is recommended that more of yellow coloured liquid detergent should be produced for sales by the producer to enhance profitability.
\end{abstract}

Keywords: Liquid detergent, Linear alkyl benzene sulphonic acid (LABSA), colorant, caustic soda

\section{INTRODUCTION}

Petrochemicals in general, are compounds and polymers derived directly from petroleum, used in the chemical market. Among the major petrochemical products are plastics, synthetic fibres, synthetic rubber and detergents. Detergents are surface active agents used for removing dirt and stains [1]. In other words, it is a surfactant which aids the cleaning action of water by reducing its surface tension. It concentrates at oil-water interfaces, exert emulsifying action and hence, aids in removing stain.[1-2] They have water-attracting (hydrophilic) groups on one end of the molecule and water repelling (hydrophobic) groups on the other end. Detergents are divided into four main groups: Anionic detergents, Cationic detergents, Non-ionic detergents, Amphoteric detergents [3-5]. The largest group is the anionic detergents which are usually of sodium salts of an organic sulfate or sulphonate. They can be formulated to produce a product of the desired characteristics, ranging from maximum cleaning power, maximum cleaning/unit cost to maximum biodegradable. Detergency however, is the theory and practice of dirt removal from solid surface by surface chemical means like adsorption at interfacial tension, solubilization, emulsification and the formation and description of surface changes [6-7]. In a process to produce a detergent containing a sulfur acid formation, the alkyl-benzene is introduced continuously into the sulfonation with the requisite amount of oleum to control the heat of sulfonation conversion and maintain the temperature at about $55^{\circ} \mathrm{C}$. Surfactants as liquid detergents provide the ability to penetrate and wet solid surface such as stained fabric, dirty dishes most specially to displace, soluble, solubilize or emulsify various soils, particularly oils and greases and to dispose or suspend certain soil in solution to prevent their re-position.

Detergents especially the liquid ones used in dish washing have to be effective in removing a wide range of soil e.g. dust perspiration, ink, spots, soot, blood stain, food stains, etc. There are vital properties a good detergent should possess in order to clean effectively. They include ability to wet the surface involved, ability to dislodge or disband the dirt-bonds and ability to suspend the dirt until it is finally rinsed away. Cleaning a surface might just require a water wash, a hot water wash, or a steam jet. Temperature and purity of the water or steam used will depend on the 
material to be cleaned and the process. Although cleaning may require soap or detergents of some kind, manufacturer's precaution needs to be observed for reasons of safety and environmental considerations. For examples many detergent companies now advertise their phosphate-free content to people supporting the environment. Although domestic detergents especially the liquid ones are not classified as poisonous, many large laundry facilities e.g. those in large hotels, ask that clients conserve the use of linens and soap to reduce the effects of detergent solution in some effluents. Phosphates in detergents are among the 'nutrients' in ocean environments, higher levels of which are attributed to accelerating the growth of 'red-tide' algae. Hence, the need to study the effectiveness of liquid detergents. Liquid detergent has been a major and most effective replacement to the production of soaps due to its good of efficiency which is about $15 \%$ more efficient than soap and more economical [5-7]. Detergents remain unaffected by the presence of naturally occurring line and metallic salts/ions in hard water and hence, maintained its cleaning potential with practically no wastage and even remain active in acid /water solution. In industries and factories, where cleanliness is as important as production liquid detergents are employed to provide a sanitized environment. In textile industry use of liquid detergent for scoring the fibres and yarns are not left out. Also, in petroleum refinery plants where prolonging the life of drilling bits. Liquid detergents also find application in light and heavy dirty engineering work, required as a degreasing product or agent to remove unwanted lubricants and preservatives. Garage and auto-repair stops also use it in cleaning car engines and chasis of cars before repairs.

\section{MATERIALS AND METHODS}

\subsection{Materials}

The raw materials used for the production of the liquid detergent were industrial grade products obtained from approved Chemical Market, Ojota in Lagos, Nigeria. These ingredients include Linear Alkyl benzene sulphonic acid (LABS), Caustic soda, colourant /dye / pigment, Perfume, Preservatives and Other additives. The colourants used were water based. Five colourants used were pink, Blue, green, yellow, and glo green in colour. The main equipment used for the production and analysis are weighing balance, plastic and glass beaker, stirring rod, density bottle, capillary viscometer and digital $\mathrm{pH}$ meter

\subsection{Methods}

The production of liquid detergent involves the combination of all the raw materials in a reactor with an activated stirrer to aid uniformity or homogeneity of the material.

The basis of the production was 100g. The needed amount (as shown in Table 1) of Carboxy Methyl Cellulose (CMC) was weighed in a plastic beaker and it is soaked for $20 \mathrm{hrs}$ until curing is attained. The needed amount of water was weighed into a glass beaker using analytical weighing balance. About three quarter $(3 / 4)$ amount of this water was poured into $1000 \mathrm{ml}$ plastic beaker and the needed amount of caustic soda salt was added (after being weighed). The stirring rod was used to accomplish a homogenous and evenly distributed solution. The long chain organic acid, linear alkyl benzene sulphonic acid (LABSA) was added slowly with mild, subsurface agitation to ensure an even distribution, resulting in a thick white foamy substance. The reacting container (1000ml plastic beaker) became warn after mixing due to the exothermic nature of this neutralization reaction of LABSA by caustic soda to form the sodium salt of the sulphonic acid.

The other components, known as additives (perfume, colourant and preservatives) were added in succession with continuous agitation of the mixture using the stirring rod. The remaining one quarter (1/4) amount of water was then added and the mixture was stirred thoroughly. The product was allowed to settle down (cure) for some hours and then analyzed. The samples prepared were six in all; five samples doped with the five different colours of colourant (samples A1 - A5) and sample B that does not contain any colorant. The colours of the colourant used were pink, Blue, green, yellow, and green.

Akinyemi, $2019 \quad 2 \quad$ www.etrj.com.ng
(c) 2019 Faculty of Engineering, Lagos State University, Ojo. Nigeria. All rights reserved.


Table 1 Material Compositions for Production of 100g Liquid detergent Sample

\begin{tabular}{llll}
\hline S/N & Materials & Quantity \\
\hline 1 & Linear Alkybenzene & Sulfonic acid & 18.5 \\
2 & (LABS) & Caustic soda & 4.66 \\
3 & Preservatives: formalin & 0.2 \\
4 & Colourant/dye: water based/Oil based & 0.1 \\
5 & Perfumes & 0.5 \\
6 & Water & 48.32 \\
7 & Other additives (including CMC) & 27.72 \\
\hline Total & 100 \\
\hline
\end{tabular}

\subsection{Analysis of Liquid Detergent samples}

The cured liquid detergent was analysed based on the following test

$>\mathrm{pH}$

$>$ specific gravity

$>$ appearance and odour/smell test

$>$ viscosity

pH test on liquid detergent: The equipment used for the test were $\mathrm{pH}$ meter and plastic beaker. The samples to be analyzed were poured into a plastic beaker and the electrode of the $\mathrm{pH}$ meter was inserted in it. The $\mathrm{pH}$ reading of the sample was indicated on the $\mathrm{pH}$ meter by the corresponding movement of the reading pen or dial.

Specific Gravity Test: The equipment used for the analysis are analytical weighing balance and density bottle. The reagents used were water and the liquid detergent sample. The $50 \mathrm{ml}$ density bottle was weighed empty on the weighing balance and its weight with its cover was recorded as $\mathrm{w}_{1}$. The bottle was filled with water to the brim and covered (excess water overflow through the perforations in the cover) and weighed on the analytical balance. The weight was recorded as $\mathrm{w}_{2}$. The water was poured away and the container dried. The container was then filled with the liquid detergent sample to the brim and covered (excess water overflow through the perforations in the cover) and weighed on the weighing balance. The weight was recorded as $w_{3}$. The specific gravity of the liquid detergent sample was determined using equation (1).

$\rho=\frac{w_{3}-w_{1}}{w_{2}-w_{1}}$

Where

$\rho \quad=\quad$ specific gravity

$\mathrm{w}_{1}=\quad$ weight of the $50 \mathrm{ml}$ density bottle

$\mathrm{w}_{2}=$ weight of the bottle + weight of water

$\mathrm{w}_{3}=$ weight of bottle + weight of liquid detergent

Viscosity Test: The liquid detergent sample was poured into the capillary viscometer and allowed to flow into through it between the upper and lower mark. The time taken for the flow was recorded for each sample using a stop watch. The value of the kinematic viscosity for each sample was determined using equation (2).

$v=k t$

Where

v $=$ kinematic viscosity

$\mathrm{k}=$ constant depending on the viscometer

$\mathrm{t}=$ time recorded for the flow 
Appearance and Odour/Smell test: The appearance test was carried out simply by looking at the liquid detergent samples in a clear glass beaker while the odour/smell test was carried out by perceiving the sample, using the sense of smell organ, the nose. This test indicated if the amount of colourant and perfume used in the sample is adequate, sufficient or excess.

Marketability Test: This was done by deploying a questionnaire to different category of consumer that make use of liquid detergent within Lagos State of Nigeria. Total number of respondents used for the analysis was 200 people.

\section{RESULTS}

The appearance of the produced liquid detergent samples are shown in Table 2 to be pink for A1, Blue for A2, green for A3, yellow for A4and glo green for A5. The blue did not have any clear colour. The addition of different colourant does not have any impact on the odour of the samples tested as shown in Table 3 The Jasmine odour of the perfume added to the liquid detergent was retained irrespective of the colour of the colourant added to the samples. This implies that the addition of colourant to the liquid detergent does not have any effects on the odour of the products. From the results obtained the addition of colourant increased the $\mathrm{pH}$ of the liquid detergent sample slightly in some cases (Figure 1). For instance, samples A1 and $\mathrm{A} 2$ increased the $\mathrm{pH}$ from 6.8 to 7.0. This is a favourable increment because it tends to make the detergent to have neither acidic nor alkali behaviour. Sample A4 (yellow) exhibited no change in $\mathrm{pH}$ when compared with the sample without colour (sample B. The least $\mathrm{pH}$ value observed for all the samples produced was 6.8 and highest $\mathrm{pH}$ as exhibited by samples A1 and A2 was 7.0. Samples A3 and A5 exhibited similar pH value of 6.9.

Table 2 Appearance of Liquid detergent Samples

\begin{tabular}{ll}
\hline Sample & Appearance \\
\hline A1 & Pink \\
A2 & Blue \\
A3 & Green \\
A4 & Yellow \\
A5 & Glo green \\
B & No colour \\
\hline
\end{tabular}

Table 3 Odour of Liquid detergent Samples

\begin{tabular}{ll}
\hline Sample & Time (seconds) \\
\hline A1 & Jasmine \\
A2 & Jasmine \\
A3 & Jasmine \\
A4 & Jasmine \\
A5 & Jasmine \\
B & Jasmine \\
Standard range & Typical jasmine \\
\hline
\end{tabular}

The whole values of $\mathrm{pH}$ observed for all the tested samples however fell within the standard $\mathrm{pH}$ value of range 6.0 7.0 expected for liquid detergent. This is in agreement with the findings previous researchers $[2,8]$ that ideally the $\mathrm{pH}$ of any liquid detergent is preferred to be at 7.0, which is neutral thus the consumer is protected from any hazard which can arise from either an acidic or alkaline sample.

Furthermore, addition of colourant increased the specific gravity of the liquid detergent in different capacity (Figure 2). The colourant added to Sample $A_{2}$ increased the specific gravity of the liquid detergent most while colourant added to sample $\mathrm{A}_{3}$ and $\mathrm{A}_{4}$ displayed the least increment. The specific gravity of sample without any colour was quite low and equal to the minimum value (1.064) though still fell within range of the standard values. All the specific gravity values obtained for all the samples were within range of the standard values of $1.064-1.084$. Hence, the addition of the colourant did not have any negative effects on the liquid detergent.

It was also observed that the addition of colourant affected the viscosity of the liquid detergent (Figure 3 ). The colourant increased the viscosity of the samples slightly, though within the standard range. The increment was however very little when compared with sample without chemical additive. The increment may be to the advantage of the product. 


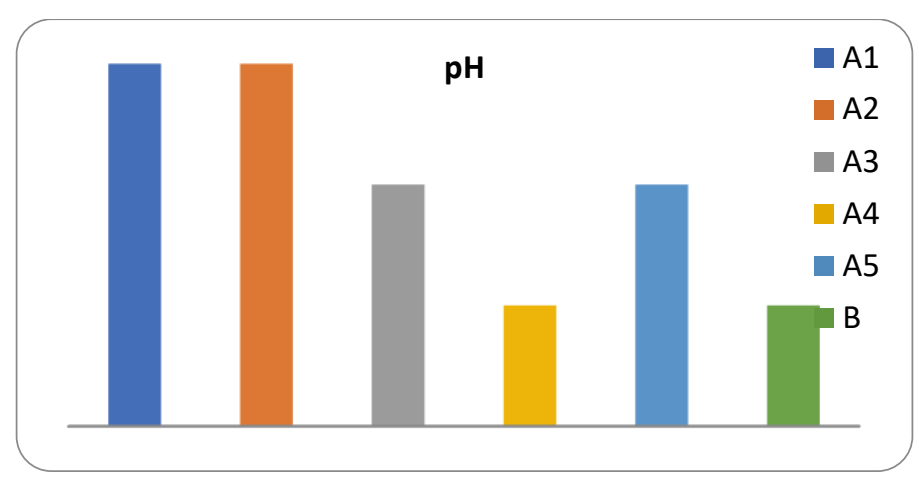

Figure 1 Impact of colourant on the $\mathrm{pH}$ of the liquid detergent

The results showed that liquid detergent brand have bright and beautiful colour which helps to increase its appeal to the consumers (Figure 4). It was ultimately observed that the yellow coloured liquid detergent is the most preferred by the consumers (Figure 4). The analysis of the questionnaires revealed that majority of the respondents preferred yellow coloured detergent to the other colour considered. About 50\% of the users (respondents) preferred yellow coloured (A4) liquid detergent. The least preferred colour for liquid detergent is glo green (12\%), followed by green colour. Only about $15 \%$ of the consumers preferred pink and blue coloured liquid detergent (see Figure 4).

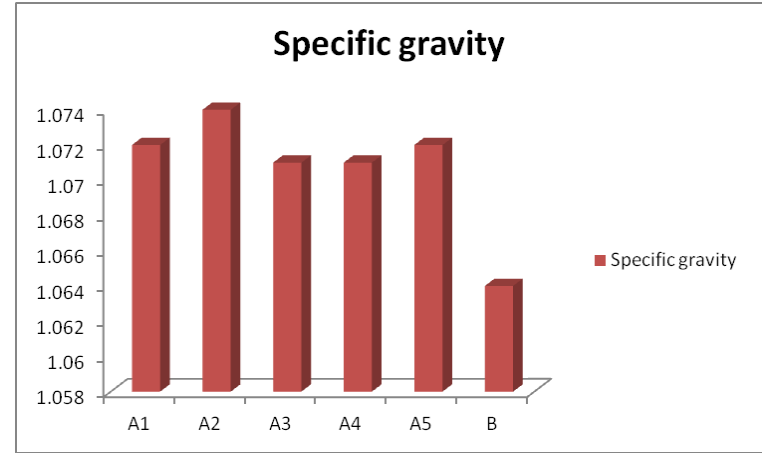

Figure 2. Effects of colourant on specific gravity of the liquid detergent

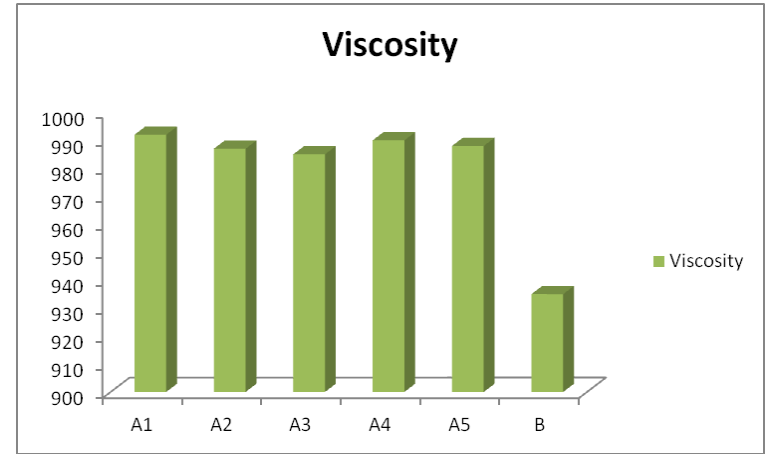

Figure 3. Effects of colourant on Viscosity (cSt) of the liquid detergent

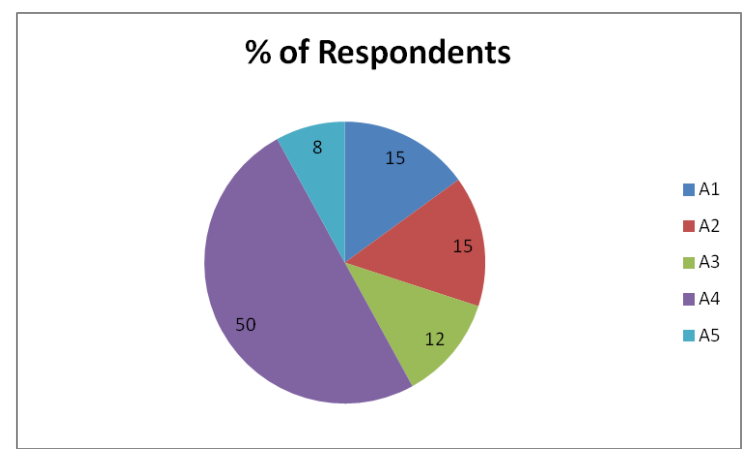

Figure 4. Market Acceptability of the liquid detergent based on the colour of the colourant 


\section{CONCLUSION}

Colourant was observed to be among the variables which act as deciding factor in proceeding or halting the full-scale production of any product. It could be used to stir a renewed interest in an existing brand. Thus it serves as market strategy employed by the manufacturer. From the results obtained in this study, it could be concluded that quality liquid detergent which meets appropriate standard could be produced locally. It could also be concluded that liquid detergent is an efficient household product which has neither acidic nor alkaline nature and capable of thorough cleansing of dirt with any danger of attack on skin when in contact with it. It could be also concluded that colourant does not affect the quality of liquid detergent negatively. However, it was observed that yellow coloured liquid detergent is more preferred by the users. It is recommended that bright and sharp colours should be used in the production of liquid detergent. The addition of anti-redeposition agent for instance, carboxylmethyl cellulose (CMC) within the range of $0.1 \%-0.15 \%$ composition by weight is also recommended to prevent redeposition of dirt and stain on the cleared surface.

\section{REFERENCES}

[1]Henrik, L., Svend, G. K., Peter, S., Lene, J., Christian, I.J., Macro, W. (2012). Protease and Amylase Stability in the presence of Chelators Used in Laundry Detergent Applications: Correlation between Chelator Properties and Enzyme Stability in Liquid Detergent. Journal of Surfactant Detergent, Volume 15, 2012, pp. 265 - 276.

[2] Azeez O. S.and Abegunde G. S.(2016). Production And Characterization of Liquid Detergents from Some Agricultural Waste Products, Nigeria Journal of Technology, vol.35(1),pp.60-65.

http://dx.doi.org/10.4314/njt.v35i1.10

[3] Kent A. J. (1983). Riegel's handbook on industrial chemistry. $8^{\text {th }}$ edition, Van Nostrand Reinhold Co. New York.

[4] Mc-Graw Hill (1982). Encyclopedia of science and Technology. $5^{\text {th }}$ edition, 12, Mc-Graw Hill Inc. New York.

[5] Werner Dabelstein, Arno Reglitzky, Andrea Schütze, Klaus Reders "Automotive Fuels" in Ullmann's Encyclopedia of Industrial Chemistry 2002, Wiley-VCH, Weinheimdoi:10.1002/14356007.a16_719.pub2

[6] Koley D, Bard AJ (2010). "Triton X-100 concentration effects on membrane permeability of a single HeLa cell by scanning electrochemical microscopy (SECM)". Proceedings of the National Academy of Sciences of the United States of America. 107 (39): 16783-7.

[7] Lichtenberg D, Ahyayauch H, Goñi FM (2013). "The mechanism of detergent solubilization of lipid bilayers". Biophysical Journal. 105 (2): 289-299. doi:10.1016/j.bpj.2013.06.007.

[8] Mahatta T. L. (1983). Soap, detergents, oil and fats (manufacturing and application) S. B. P. Board Publication New Delhi, India. 